including a glass jug (Roman) and a large earthenware pot. Other finds have been made-chariot harness and gear, a slave charm and implements. It is thought that the position, occupying about 25 acres on the top of a hill, being a natural strong point, may have been held as a camp up to the time the Romans occupied the valley where Canterbury now stands. Cuttings have been made on the north side and have brought to light a ditch fillud with rubble, broken earthenware and vegetable matter. The excavators have also found a rampart and a black occupational level which contains much broken pottery. More pottery was found in a cess-pit, but a cooking pit, flint-lined, serving a group of wattle and daub huts, contained little pottery. Excavations have also been begun on the south side, whence most of the previous material has come.

\section{Control of the Bed-bug}

THE Ministry of Health has recently issued two brochures dealing with the bed-bug, its habits and methods of eradication. While this insect is not known to be actually concerned with the transmission of the pathogenic organisms of any specific disease, its presence in large numbers is a menace to humanity. The insect is perhaps responsible for ill-health from lack of sleep due to skin irritation, and its presence accentuates the already insanitary conditions under which it thrives. During recent years, the problem of its eradication has come more and more into prominence in connexion with slum clearance and other schemes. A large number of tenants 'of 'council houses' come from verminous dwellings, and the need for ensuring that the new houses are not similarly infested from the outset is a matter of concern to the local authorities. A report of the Committee on the Eradication of Bed-bugs has recently been issued (Reports on Public Health and Medical Subjects. No. 72. 1934.46 pp. H.M. Stationery Office, $1 s .0 d$. net). This Committee, under the chairmanship of Dr. G. W. Monier-Williams, has, in its report, summarised the present position and indicated the lines along which future work on bed-bug control might be profitably undertaken. The life-history of the insect is discussed, and various methods of control are dealt with. In view of the lack of accurate information as to the bionomics and habits of the insect, various lines are emphasised along which research requires to be carried out. The report is accompanied by two well-executed coloured plates, illustrating various phases in the life of the insect, together with an excellent annotated bibliography.

ThE second brochure issued by the Ministry of Health on this subject (Memo. 180 Med.) is entitled "Memorandum on the Bed-bug and how to deal with it". It is intended for official use and has been prepared with the view of assisting sanitary officers and others in dealing with bed-bugs. It outlines the biology of the insect, gives instructions where to seek the insects, and cites the chief means of prevention and the best methods of extermination. For fuller information on the subject the report, already mentioned, should be referred to. The memorandum is accompanied by the same coloured plates as are appended to the report. We welcome the appearance of these two publications since they supply, in non-technical language, accurate and upto-date information on a long-standing problem. Its full solution is dependent upon research carried out along the lines indicated, and much remains to be done. Relatively little is known, for example, of the effects of climatic conditions on the breeding of the insect, or as to the extent to which it can survive on the blood of other animals in the absence of human beings. There is, also, much yet to be discovered with regard to the differential action of insecticides on the insect and its eggs. The effects of heavy infestation of bed-bugs on the general health of the people are still not properly understood, and there is real need for definitely ascertaining whether, under certain conditions, bed-bugs may prove to be the carriers of disease germs.

\section{A New Skymeter}

IN these days when many of our great cities are involved in so much rebuilding, the question of light easements of adjoining property frequently gives rise to the necessity for financial settlements or building restrictions involving a definite assessment of rights of light existing. Speaking generally, the law recognises that light enjoyed over a sufficient period, so far as the use to which the particular space lighted is usually put, cannot be materially encroached upon without some form of compensation. At one time, cases in the courts depended on such general evidence as could be brought forward ; more recently, geometrical methods have been worked out whereby the actual illumination can be measured. These methods are laborious, and Mr. A. S. E. Ackermann, 17 Victoria Street, London, S.W.I, sends us particulars of an invention for determining sill ratios which involves neither photographic nor photometric work. It consists of a pane of clear glass attached to two adjustable radius bars, the whole mounted on a stand. This is set up to face the window in question with the centre of the glass at the middle of the sky area. The sine of the elevation is read and the sky area traced on the glass, the observer using a pinhole eyepiece. This diagram is transferred to tracing paper and the sky area measured by a planimeter. This area multiplied by the sine of the elevation angle and divided by a constant gives the sill ratio. The instrument is portable and weighs less than $9 \mathrm{lb}$.

\section{Skating Rinks and Wave Bathing Pools}

ICE skating rinks and wave bathing pools, being used mainly for pleasure, have until quite recently not been seriously studied from the engineering and scientific point of view. The Dolder ice skating rink at Zurich which was opened four years ago has proved such a success that Zurich is now the centre of the ice sports in Switzerland. In the Escher-Wyss News of May 1934, D. Mettler describes the open-air skating rink and wave bathing pool in Berne and 